\title{
THE EFFECT OF OPERATING SYSTEMS AND TYPES OF APPS ON PURCHASE INTENTION
}

\author{
Hsiu-Li Liao, Chung Yuan Christian University, hsiuliliao@cycu.edu.tw \\ Su-Houn Liu, Chung Yuan Christian University, vandy@cycu.edu.tw \\ Chih-Chung Cheng, Chung Yuan Christian University, abcdefg303739@gmail.com
}

\begin{abstract}
Rapid growth of the smartphone and tablet computer market has facilitated the development of applications on mobile platforms such as "The App Store" from Apple, "Google Play" from Google, and "Marketplace" from Windows Phone. The aims of this study are to understand whether different operating systems and types of apps affect purchase intention. To test the research hypotheses, 200 volunteers were recruited on the PTT Bulletin Board System in Taiwan to participate in the experiment. At the end of the experiment, 197 copies of completed, valid responses were collected. The study randomly assigned the participants into one of four groups (Android-functional, Android-entertainment, IOS-functional, IOS-entertainment). Results showed that the app types influence their users' perceptions of relative advantage and compatibility. There are significant differences in the perceptions of compatibility, complexity, price, interpersonal influence, and purchase intention for using apps developed on different operating systems. Gender has no impact on users' perceptions of the characteristics of innovation, price, interpersonal and external influence, and purchase intention.
\end{abstract}

Keywords: Perceived Characteristics of Innovation (PCI), Price, Interpersonal Influence, External Influence, Purchase Intention

\section{INTRODUCTION}

Rapid growth of the smartphone and tablet computer market has facilitated the development of applications on mobile platforms such as "The App Store" from Apple, "Google Play" from Google, and "Marketplace" from Windows Phone. The total number of apps available today is about 1.5 million. The App Store has the greatest number of apps at 710,000, followed by Google Play, which owns 510,000 apps (MIC, 2012). These mobile application platforms provide developers of application software with opportunities for innovation and potential business development. According to estimates by research2guidance (a company that specializes in mobile app research), the global app market grew from US\$ 1.94 billion in 2009 to US\$ 15.66 billion in 2013, and witnessed an annual growth rate of $68.53 \%$. Moreover, this market has become a new gold mine for a number of software developers (Ho, T. L., Hsu, H. H., \& Chang, C. C., 2012). Ovum pointed out that the total income from global apps amounted to US\$ 4.1 billion in 2011, and is projected to reach US\$ 7.1 billion in 2016. Therefore, the vast business potential of apps cannot be ignored.

\section{Perceived Characteristics of Innovation}

Factors such as users' psychology, cognition, and external environment influence a user's decision in the adoption of an innovative product. Rogers (1995) proposed five types of cognition with regard to innovative adoption: (1) Relative advantage: When a user perceives that a new product has more usefulness than an existing one, the probability that the former will be adopted is higher; (2) Compatibility: If a new product is consistent with an existing technology with respect to user values, past experiences, and needs, it is accepted more easily; (3) Complexity: The harder it is for a user to understand or use a new product, the more difficult it is for a new product to be accepted; (4) Triability: The process of adopting a new product is often partially experimental and partially correctional; and (5) Observability: If a product's utility can be easily observed, the probability of adoption is higher.

\section{Price}

In marketing and economics, price formation is an important factor frequently researched by scholars. Hawkins et al. (1998) suggested that price is the compulsory monetary amount that a consumer is required to pay to obtain a 
product. They implied that the higher the amount, the lower the purchase intention. Furthermore, a study by Alba et al. (1997) showed that online shopping can reduce consumers' search for pricing information and make them more sensitive to the prices of products. If a product's online price is lower than its price in a physical store, consumers' purchase intention will increase significantly.

\section{Environmental Variables}

Engel, Blackwell, and Miniard (1993) believed that consumers' buying decisions are affected by environmental factors as well as other factors pertaining to individual differences. Environmental factors include culture, subculture, social class, personal influence, family influence, context, and other influences. Taylor and Todd (1995) suggested that environmental variables should be divided into two categories: peer influence and superior influence. Holak (1998) proposed that new products can adopt price ranges and time needs in the model as environmental variables.

\section{Interpersonal Influence}

Research by Bhattacherjee (2000) on online banking revealed that interpersonal influence is a combination of peer influence and superior influence, and an individual's decision to use new technology is influenced by his/her peers, superiors, friends, and relatives. On the other hand, he stated that an individual's decision to adopt a new technology is influence by external influences, which he defines as those arising from broadcasting media, newspapers and magazines, experts, and rankings. His study also revealed that interpersonal and external influences both significantly influence purchase intention. However, the impact of interpersonal influence is stronger than that of external influences, thereby explaining why users tend to believe the experiences of earlier users.

\section{External Influence}

Karahanna, Straub, and Chervany (1998) defined social influences as external social factors influencing individuals' behavior in adopting innovative technology. In addition, Hsu and Lu (2004) pointed out that social influences include two formations: social norms and critical mass. These formations influence purchase intention via external social environmental factors. All forms of media play a crucial role in affecting individuals' thoughts and behavior. Consumers often agree to adopt a product based on media opinions.

\section{Research Purpose and Questions}

The vibrant app market in recent years has resulted in substantial research exploring the technology of app development and the application of various services. Under the market orientation of "customer first", the needs of customers have become a driving force to innovation. Therefore, only by understanding the key factors of customers' needs before developing an app can be created with higher utility. Hence, understanding customers' preferences prior to developing an app is vital. Therefore, the aims of this study are to understand whether different operating systems and types of apps affect purchase intention. Our research centered upon the following research questions: (1) Do the different app types affect perceived characteristics of innovation, price, environmental variables, and purchase intention? (2) Do the different app operating systems influence perceived characteristics of innovation, price, environmental variables, and purchase intention?

\section{Research Hypotheses}

The research hypotheses to be tested are as follow:

$\mathrm{H}_{1}$ : The different app types affect perceived characteristics of innovation, price, environmental variables, and purchase intention.

$\mathrm{H}_{1 \mathrm{a}}$ : The different app types affect perceived relative advantage, compatibility. and complexity.

$\mathrm{H}_{1 \mathrm{~b}}$ : The different app types affect perceived price.

$\mathrm{H}_{1 \mathrm{c}}$ : The different app types affect interpersonal influence and external influence.

$\mathrm{H}_{1 \mathrm{~d}}$ : The different app types affect purchase intention. 
$\mathrm{H}_{2}$ : The different app operating systems influence perceived characteristics of innovation, price, environmental variables, and purchase intention.

$\mathrm{H}_{2 \mathrm{a}}$ : The different app operating systems influence perceived relative advantage, compatibility, and complexity. $\mathrm{H}_{2 \mathrm{~b}}$ : The different app operating systems influence perceived price.

$\mathrm{H}_{2 \mathrm{c}}$ : The different app operating systems influence interpersonal influence and external influence.

$\mathrm{H}_{2 \mathrm{~d}}$ : The different app operating systems influence purchase intention.

\section{RESEARCH METHODOLOGY}

To test the research hypotheses, the researchers recruited 200 volunteers on the PTT Bulletin Board System in Taiwan to participate this experiment. The app types in the study were divided into functional apps and entertainment apps. The app operating systems used in the experiment were Android and IOS. Based on the two (functional versus entertainment) by two (Android versus IOS) experimental design, each participant was randomly assigned into one of four groups (Android-functional, Android-entertainment, IOS-functional, or IOS-entertainment). Each group included 50 participants.

The researchers selected three apps of each type from Google Play and The App Store. Each app had been developed on both Android and IOS at the same time. Functional apps chosen were PAPAGO! Taiwan, English King, and Food Convenience (Figure 1). Entertainment apps chosen were FINAL FANTASY III, Plants vs. Zombies, and Candy Crush Saga (Figure 2). Each subject selected one of the three apps appropriate to his/her group assignment. After reading an introduction to the app selected, the subject completed the questionnaire. At the end of the experiment, 200 copies of the questionnaire were distributed; of those, 197 copies of completed, valid responses were collected. Divided by gender, 132 of the participants were male (68\%) and 61 were female (32\%).

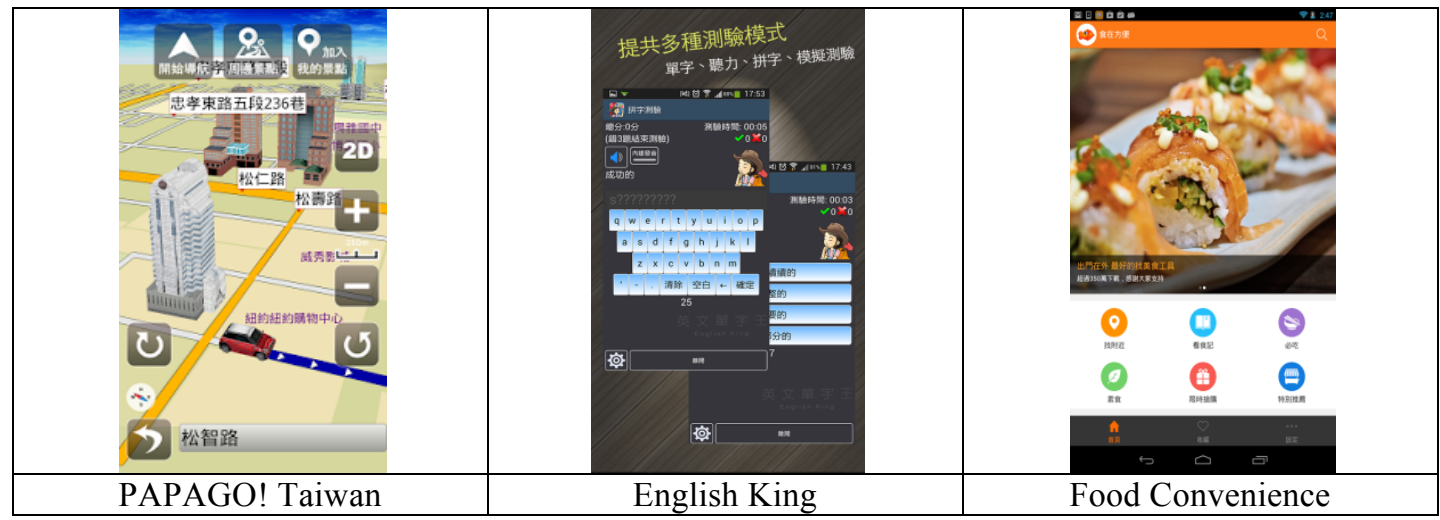

Figure 1. Three functional apps

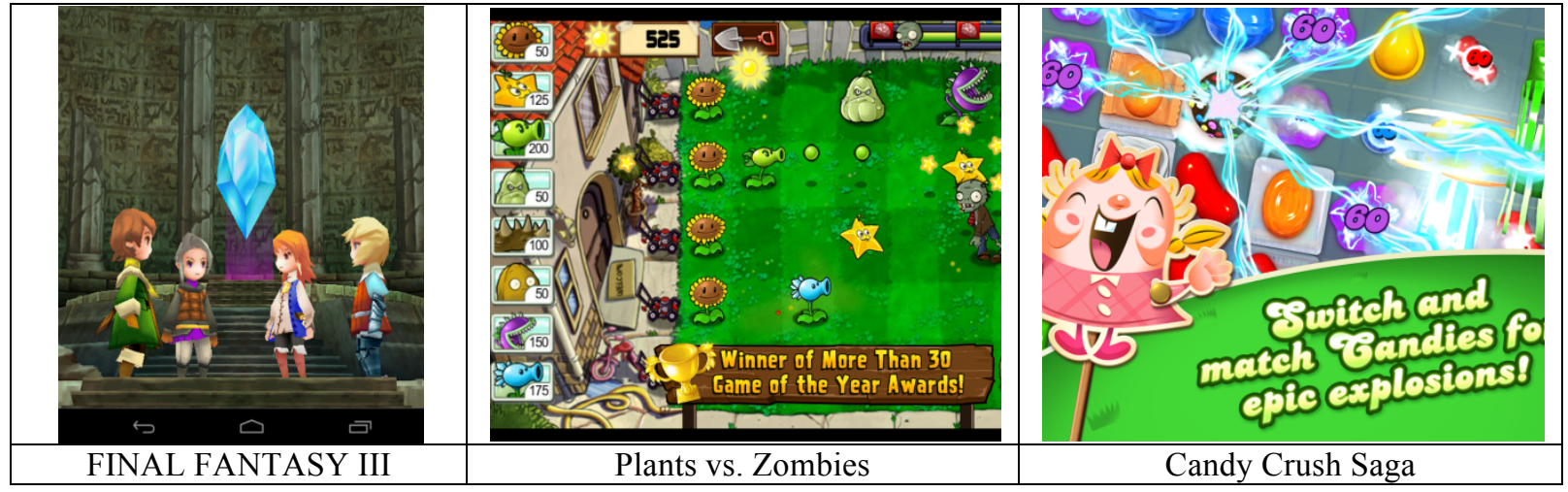

Figure 2. Three Entertainment Apps 


\section{RESULTS}

Reliability is a measurement to assess the consistency of items (Wiersma, 2000). According to Nunnally (1978), the alpha-level of the sample indicates a reasonable level of reliability $(\alpha>0.70)$, and thereby, reveals adequate internal consistency in the study (Table 1). The factor loading of each construct is larger than 0.6. Both the convergent validity and discriminant validity in the research model were adequate.

Table 1. Construct Means, Standard Deviations, and Reliabilities

\begin{tabular}{|c|c|c|c|c|c|}
\hline Construct & Item & Mean & Standard Deviation & Factor Loading & Cronbach's $\alpha$ \\
\hline \multirow{5}{*}{$\begin{array}{l}\text { Relative } \\
\text { advantage }\end{array}$} & RA_1 & 4.53 & 1.447 & 0.884 & \multirow{5}{*}{0.769} \\
\hline & RA_2 & 4.70 & 1.418 & 0.825 & \\
\hline & RA_3 & 4.37 & 1.424 & 0.826 & \\
\hline & RA 4 & 5.69 & 1.069 & 0.731 & \\
\hline & RA_5 & 5.70 & 0.986 & 0.739 & \\
\hline \multirow{4}{*}{ Compatibility } & $\mathrm{CO} 1$ & 5.84 & 1.202 & 0.699 & \multirow{4}{*}{0.795} \\
\hline & $\mathrm{CO} 2$ & 5.34 & 1.063 & 0.884 & \\
\hline & $\mathrm{CO} 3$ & 5.04 & 1.136 & 0.818 & \\
\hline & $\mathrm{CO}_{4} 4$ & 5.60 & 1.062 & 0.755 & \\
\hline \multirow{4}{*}{ Complexity } & COM_1 & 5.79 & 1.075 & 0.728 & \multirow{4}{*}{0.882} \\
\hline & COM_2 & 5.79 & .973 & 0.826 & \\
\hline & COM 3 & 5.70 & .943 & 0.673 & \\
\hline & COM 4 & 5.67 & .921 & 0.741 & \\
\hline \multirow{4}{*}{ Price } & $\mathrm{P} \_1$ & 5.38 & 1.136 & 0.687 & \multirow{4}{*}{0.758} \\
\hline & $\mathrm{P} \_2$ & 5.52 & 1.204 & 0.717 & \\
\hline & P_3 & 4.87 & 1.081 & 0.639 & \\
\hline & $\mathrm{P} 4$ & 5.81 & 1.020 & 0.770 & \\
\hline \multirow{4}{*}{$\begin{array}{l}\text { Interpersonal } \\
\text { influence }\end{array}$} & IE 1 & 4.48 & 1.275 & 0.853 & \multirow{4}{*}{0.816} \\
\hline & IE_2 & 4.79 & 1.108 & 0.856 & \\
\hline & IE_3 & 4.78 & 1.301 & 0.834 & \\
\hline & IE 4 & 4.56 & 1.496 & 0.697 & \\
\hline \multirow{3}{*}{ External influence } & EE_1 & 4.45 & 1.258 & 0.816 & \multirow{3}{*}{0.919} \\
\hline & EE_2 & 4.55 & 1.369 & 0.917 & \\
\hline & EE_3 & 4.68 & 1.302 & 0.849 & \\
\hline \multirow{4}{*}{ Purchase intention } & PUI_1 & 5.33 & 1.082 & 0.873 & \multirow{4}{*}{0.921} \\
\hline & PUI_2 & 5.37 & 1.116 & 0.882 & \\
\hline & PUI_3 & 5.32 & 1.150 & 0.857 & \\
\hline & PUI_4 & 5.06 & 1.271 & 0.664 & \\
\hline
\end{tabular}

Data associated with all constructs were analyzed using the independent sample t-test on all constructs are summarized in Table 2, Table 3, and Table 4. The app types do not influence all constructs. The app types influence their users' perceptions of relative advantage $(\mathrm{F}=33.440, \mathrm{p}=0.000)$ and compatibility $(\mathrm{F}=5.392, \mathrm{p}=0.021)$, as seen in Table 2. The users perceive that functional-type apps have a higher degree of relative advantage and compatibility than entertainment-type apps.

The app's operating system influences users' perceptions of compatibility $(\mathrm{F}=8.518, \mathrm{p}=0.004)$, complexity $(\mathrm{F}=6.868$, $\mathrm{p}=0.009)$, price $(\mathrm{F}=5.221, \mathrm{p}=0.023)$, interpersonal influence $(\mathrm{F}=3.797, \mathrm{p}=0.053)$, and purchase intention $(\mathrm{F}=6.618$, $\mathrm{p}=0.011$ ), as shown in Table 3. The users perceive a higher degree of compatibility, complexity, price, interpersonal influence, and purchase intention of IOS apps than those of Android apps. 
Table 2. The Impact of App Types on All Constructs

\begin{tabular}{|c|c|c|c|c|c|c|}
\hline Construct & Types & \begin{tabular}{|c|} 
Number of \\
Samples
\end{tabular} & Mean & $\begin{array}{l}\text { Standard } \\
\text { Deviation }\end{array}$ & F-value & P-value \\
\hline \multirow{2}{*}{$\begin{array}{l}\text { Relative } \\
\text { advantage }\end{array}$} & Functional & 94 & 5.3660 & 0.83196 & \multirow{2}{*}{33.440} & \multirow{2}{*}{$0.000 * * *$} \\
\hline & Entertainment & 99 & 4.6525 & 0.87951 & & \\
\hline \multirow{2}{*}{ Compatibility } & Functional & 94 & 5.6037 & 0.88248 & \multirow{2}{*}{5.392} & \multirow{2}{*}{$0.021 * * *$} \\
\hline & Entertainment & 99 & 5.3131 & 0.85591 & & \\
\hline \multirow{2}{*}{ Complexity } & Functional & 94 & 5.6436 & 0.87259 & \multirow{2}{*}{2.337} & \multirow{2}{*}{0.128} \\
\hline & Entertainment & 99 & 5.8283 & 0.80547 & & \\
\hline \multirow{2}{*}{ Price } & Functional & 94 & 5.3484 & 0.79075 & \multirow{2}{*}{0.653} & \multirow{2}{*}{0.420} \\
\hline & Entertainment & 99 & 5.4394 & 0.77352 & & \\
\hline \multirow{2}{*}{$\begin{array}{l}\text { Interpersonal } \\
\text { influence }\end{array}$} & Functional & 94 & 4.6090 & 1.05275 & \multirow{2}{*}{0.321} & \multirow{2}{*}{0.572} \\
\hline & Entertainment & 99 & 4.6944 & 1.04158 & & \\
\hline \multirow{2}{*}{ External influence } & Functional & 94 & 4.5035 & 1.24793 & \multirow{2}{*}{0.413} & \multirow{2}{*}{0.521} \\
\hline & Entertainment & 99 & 4.6162 & 1.18796 & & \\
\hline \multirow{2}{*}{ Purchase intention } & Functional & 94 & 5.1463 & 1.09704 & \multirow{2}{*}{2.642} & \multirow{2}{*}{0.106} \\
\hline & Entertainment & 99 & 5.3889 & 0.97561 & & \\
\hline
\end{tabular}

${ }^{* * *} p<0.01,{ }^{* *} p<0.05,{ }^{*} p<0.1$

Table 3. The Impact of App Operating Systems on All Constructs

\begin{tabular}{|c|c|c|c|c|c|c|}
\hline Construct & $\begin{array}{c}\text { Operating } \\
\text { Systems } \\
\end{array}$ & $\begin{array}{c}\text { Number of } \\
\text { Samples } \\
\end{array}$ & Mean & $\begin{array}{l}\text { Standard } \\
\text { Deviation }\end{array}$ & F-value & P-value \\
\hline \multirow{2}{*}{$\begin{array}{l}\text { Relative } \\
\text { advantage }\end{array}$} & Android & 100 & 4.9160 & 0.89541 & \multirow{2}{*}{1.713} & \multirow{2}{*}{0.192} \\
\hline & IOS & 93 & 5.0903 & 0.95486 & & \\
\hline \multirow{2}{*}{ Compatibility } & Android & 100 & 5.2800 & 0.89208 & \multirow{2}{*}{8.518} & \multirow{2}{*}{$0.004 * * *$} \\
\hline & IOS & 93 & 5.6425 & 0.82866 & & \\
\hline \multirow{2}{*}{ Complexity } & Android & 100 & 5.5875 & 0.87066 & \multirow{2}{*}{6.868} & \multirow{2}{*}{$0.009 * * *$} \\
\hline & IOS & 93 & 5.9005 & 0.78205 & & \\
\hline \multirow{2}{*}{ Price } & Android & 100 & 5.2725 & 0.77695 & \multirow{2}{*}{5.221} & \multirow{2}{*}{$0.023^{* *}$} \\
\hline & IOS & 93 & 5.5269 & 0.76831 & & \\
\hline \multirow{2}{*}{$\begin{array}{l}\text { Interpersonal } \\
\text { influence }\end{array}$} & Android & 100 & 4.5125 & 1.08733 & \multirow{2}{*}{3.797} & \multirow{2}{*}{$0.053 *$} \\
\hline & IOS & 93 & 4.8038 & 0.98138 & & \\
\hline \multirow{2}{*}{ External influence } & Android & 100 & 4.5700 & 1.21374 & \multirow{2}{*}{0.011} & \multirow{2}{*}{0.918} \\
\hline & IOS & 93 & 4.5520 & 1.22425 & & \\
\hline \multirow{2}{*}{ Purchase intention } & Android & 100 & 5.0875 & 1.08151 & \multirow{2}{*}{6.618} & \multirow{2}{*}{$0.011 * * *$} \\
\hline & IOS & 93 & 5.4677 & 0.96278 & & \\
\hline
\end{tabular}

$* * * p<0.01, * * p<0.05, * p<0.1$ 
Gender has no significant effect on users' perceptions of relative advantage $(\mathrm{F}=1.218, \mathrm{p}=0.271)$, compatibility $(\mathrm{F}=0.068, \mathrm{p}=0.794)$, complexity $(\mathrm{F}=0.296, \mathrm{p}=0.587)$, price $(\mathrm{F}=0.006, \mathrm{p}=0.937)$, interpersonal influence $(\mathrm{F}=0.007$, $\mathrm{p}=0.933)$, external influence $(\mathrm{F}=0.005, \mathrm{p}=0.942)$, and purchase intention $(\mathrm{F}=0.168, \mathrm{p}=0.682)$, as seen in Table 4 . The results of research hypotheses examined are listed in Table 5.

Table 4. The Impact of Gender on All Constructs

\begin{tabular}{|c|c|c|c|c|c|c|}
\hline Construct & Gender & $\begin{array}{c}\text { Number of } \\
\text { Samples }\end{array}$ & Mean & $\begin{array}{l}\text { Standard } \\
\text { Deviation } \\
\end{array}$ & F-value & P-value \\
\hline \multirow{2}{*}{$\begin{array}{l}\text { Relative } \\
\text { advantage }\end{array}$} & male & 132 & 5.0500 & 0.85297 & \multirow{2}{*}{1.218} & \multirow{2}{*}{0.271} \\
\hline & Female & 61 & 4.8918 & 1.06744 & & \\
\hline \multirow{2}{*}{ Compatibility } & male & 132 & 5.4659 & 0.84131 & \multirow{2}{*}{0.068} & \multirow{2}{*}{0.794} \\
\hline & Female & 61 & 5.4303 & 0.96191 & & \\
\hline \multirow{2}{*}{ Complexity } & male & 132 & 5.7159 & 0.80716 & \multirow{2}{*}{0.296} & \multirow{2}{*}{0.587} \\
\hline & Female & 61 & 5.7869 & 0.91724 & & \\
\hline \multirow{2}{*}{ Price } & male & 132 & 5.3920 & 0.74470 & \multirow{2}{*}{0.006} & \multirow{2}{*}{0.937} \\
\hline & Female & 61 & 5.4016 & 0.86154 & & \\
\hline \multirow{2}{*}{$\begin{array}{l}\text { Interpersonal } \\
\text { influence }\end{array}$} & male & 132 & 4.6572 & 0.98141 & \multirow{2}{*}{0.007} & \multirow{2}{*}{0.933} \\
\hline & Female & 61 & 4.6434 & 1.18009 & & \\
\hline \multirow{2}{*}{ External influence } & male & 132 & 4.5657 & 1.23075 & \multirow{2}{*}{0.005} & \multirow{2}{*}{0.942} \\
\hline & Female & 61 & 4.5519 & 1.19239 & & \\
\hline \multirow{2}{*}{ Purchase intention } & male & 132 & 5.2917 & 0.91591 & \multirow{2}{*}{0.168} & \multirow{2}{*}{0.682} \\
\hline & Female & 61 & 5.2254 & 1.27778 & & \\
\hline
\end{tabular}

$* * * p<0.01, * * p<0.05, * p<0.1$

\section{CONCLUSIONS}

The study aims to examine whether apps types and operating systems play important roles in the perceptions of innovation characteristics and purchase behaviors of consumers. Responses from the users indicated that the functional apps are more usefulness than entertainment apps. They perceived that the functional apps meet their habits and demands more than entertainment apps. However, the app types have no effect on perceptions of complexity, price, interpersonal influence, external influence, and purchase intention.

There are significant differences in the perceptions of compatibility, complexity, price, interpersonal influence, and purchase intention for using apps developed on different operating systems. The users indicated that the apps on IOS meet their experiences and demands better than apps on Android. Persons using apps on IOS reported easier usage, a more reasonable price, and more interpersonal influences than persons using apps on Android. Persons using apps on IOS have a higher degree of purchase intention than the persons using apps on Android. Gender has no impact on users' perceptions of characteristics of innovation, price, interpersonal and external influence, and purchase intention. 
Table 5. The Results of Research Hypotheses

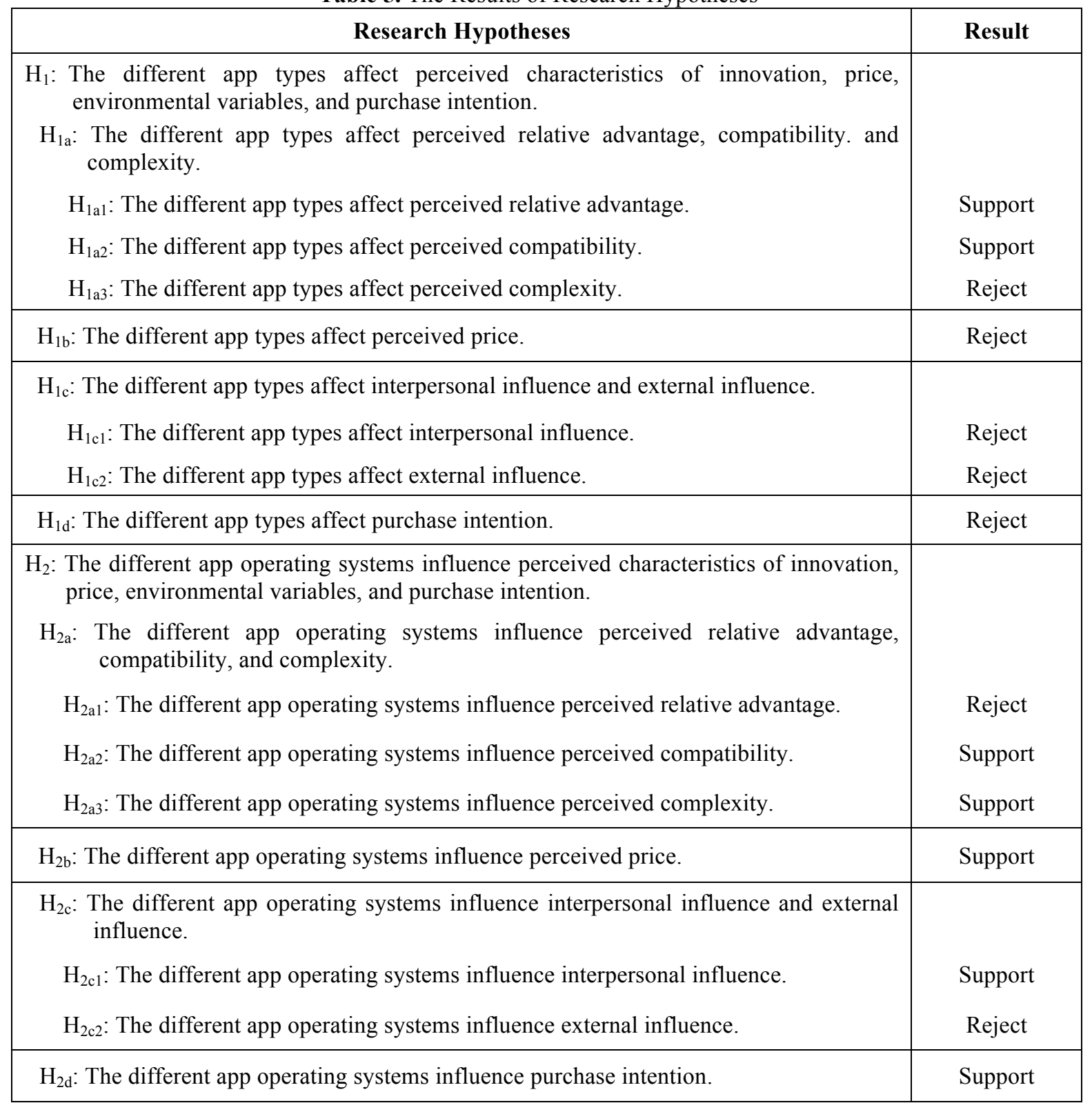

\section{REFERENCES}

1. Alba, J., Lynch, J., Weitz, B., Janiszewski, C., Lutz, R., Sawyer, A., \& Wood, S. (1997). Interactive home shopping: Incentives for consumers, retailers, and manufacturers to participate in electronic marketplaces. Journal of Marketing, 61, 38-53.

2. Bhattacherjee, A. (2000). Acceptance of e-commerce services: The case of electronic brokerages. IEEE Transactions on Systems, Man, and Cybernetics-Part A: Systems and Humans, 30(4), 411-420.

3. Engel, J. F., Blackwell, R. D., \& Miniard, P. W. (1993). Consumer behavior (7th ed.). New York: Dryden Press.

4. Hawkins, D. I., Best, R. J., \& Coney, K. A. (1983). Consumer behavior: Implication for marketing strategy (Revised ed.). Plano, TX: Business Publication. 


\section{Issues in Information Systems}

Volume 16, Issue III, pp. 156-163, 2015

5. Holak, S. L., \& Donald, R. L. (1990). Purchase intentions and the dimensions of innovation: An exploratory model. Journal of Product Innovation Management, 7, 59-73.

6. Ho, T. L, Hsu, H. H., \& Chang, C. C. (2012). User attitude and continuous purchase intention of mobile apps App store. Journal of China University of Science and Technology, 50, 169-189.

7. Hsu, C., \& Lu, H. (2004). Why do people play on-line games? An extended TAM with social influences and flow experience. Information \& Management, 41, 853-868.

8. Karahanna, E., Straub, D. W., \& Chervany, N. L. (1999). Information technology adoption across time: A cross-sectional comparison of pre-adoption and post-adoption beliefs. MIS Quarterly, 23(2), 183-213.

9. MIC (2012). The market trends and business opportunities of smart mobile devices embedded software. Taipei, Taiwan: Market Intelligence \& Consulting Institute.

10. Nunnally, J. C. (1978). Psychometric theory. New York: McGraw-Hill.

11. Rogers, E. M. (1995). Diffusion of innovation. New York: Free Press.

12. Taylor, S., \& Todd, P. A. (1995). Understanding information technology usage: A test of competing models. Information Systems Research, 6(2), 144-176.

13. Wiersma, W. (2000). Research methods in education: An introduction (7th ed.). Boston: Allyn and Bacon. 